\title{
A new high resolution computed tomography scoring system for pulmonary fibrosis, pleural disease, and emphysema in patients with asbestos related disease
}

\author{
N Al Jarad, $P$ Wilkinson, M C Pearson, R M Rudd
}

\begin{abstract}
The aim of this study was to describe a scoring system for high resolution computed tomographic (HRCT) scans analogous to the International Labour Office(ILO) scoring system for plain chest radiographs in patients with asbestos related disease. Interstitial fibrosis, pleural disease, and emphysema were scored, the reproducibility and the interobserver agreement using this scoring system were examined, and the extent of the various types of disease was correlated with measurements of lung function. Sixty asbestos workers (five women and 55 men) mean age 59 (range 34-78) were studied. The lungs were divided into upper, middle, and lower thirds. An HRCT score for the extent of pleural disease and pulmonary disease in each third was recorded in a way analogous to the International Labour Office (ILO) method of scoring pleural and parenchymal disease on chest radiographs. A CT score for the extent of emphysema was also recorded. Pleural disease and interstitial fibrosis on the plain chest radiographs were assessed according to the ILO scoring system. A chest radiographic score for emphysema analogous to that used for HRCT was also recorded. Two independent readers assigned HRCT scores that differed by two categories or less in $96 \%, 92 \%$, and $85 \%$ compared with $90 \%$, $78 \%$, and $79 \%$ of cases for chest radiographs for fibrosis, emphysema, and pleural disease respectively. There was better intraobserver repeatability for the HRCT scores than for the chest radiograph scores for all disorders. Multiple regression analysis showed that scores for interstitial fibrosis, emphysema, and pleural disease on chest radiographs and HRCT correlated to a similar degree with impairment of lung function.
\end{abstract}

The London Chest Hospital, Bonner Road, London E2 9JX, UK

N Al Jarad, P Wilkinson, M C Pearson, R M Rudd
It is concluded that the HRCT scoring system allows good inter and intraobserver agreement. The scores using the HRCT scoring system and the ILO scoring system for chest radiographs correlate with impairment of lung function to a similar extent.

Asbestos related lung and pleural disease (ARLPD) is associated with impairment of lung function, ${ }^{12}$ and is commonly assessed on chest radiographs according to the International Labour Office(ILO)classification of pneumoconioses. ${ }^{3}$ A previous study suggested that the extent of ARLPD on the plain chest radiograph according to the ILO method correlates with lung function. ${ }^{4}$

Computed tomography (CT) of the chest is superior to chest radiography in early detection of asbestosis because the decreased superimposition of structures on CT images allows a better assessment of the type, distribution, and severity of parenchymal abnormalities than is possible on plain chest radiography. ${ }^{56}$ The use of thin section CT scan and a bone algorithm reconstruction allows higher resolution images to be produced. ${ }^{7}$ This high resolution computed tomography (HRCT) is helpful in refuting or confirming the presence of pleural disease in asbestos workers and in showing additional unsuspected pulmonary disease. ${ }^{8}$

Patients with asbestosis may have, as well as pleural and parenchymal fibrosis, smoking related lung diseases such as chronic airflow limitation and emphysema. Each of these disorders may affect lung function and contribute to the overall disability. It has been shown that HRCT is sensitive in detecting early emphysema.9 Furthermore, the extent of emphysema, as assessed by a scoring system on HRCT and on the pathological specimen, correlated with lung function measurements. ${ }^{910}$

In this study we describe an HRCT scoring system analogous to the ILO method for plain chest radiographic assessment of pleural disease, emphysema, and parenchymal fibrosis. The scoring system is compared with the ILO scoring system on plain radiographs with an extension to include emphysema. Interobserver and intraobserver 
Table 1 Patient demographic data

\begin{tabular}{lllll}
\hline & Age & $\begin{array}{l}\text { Smoking } \\
\text { (pack-years) }\end{array}$ & $\begin{array}{l}\text { Duration of } \\
\text { asbestos } \\
\text { exposure }(y)\end{array}$ & $\begin{array}{l}\text { Time since } \\
\text { first asbestos } \\
\text { exposure }(y)\end{array}$ \\
\hline $\begin{array}{l}\text { Median } \\
\text { Range }\end{array}$ & 61 & 21 & 10 & 34 \\
\hline
\end{tabular}

$\star 55$ men, 5 women.

agreement on CT and chest radiographic scores are assessed and scores are correlated with lung function.

\section{Patients and methods PATIENTS}

Sixty subjects who had had previous exposure to asbestos were studied. Table 1 gives the demographic data.

Exposure to asbestos occurred through lagging in 37 , loading and unloading asbestos in the docks in 12, and building trade in six men, working in asbestos factories in three female patients, and in two female patients through handling clothes of father and husband who had been asbestos workers. They were all attending a clinic for persons who have been exposed to asbestos and all were known from plain chest radiographs to have asbestos induced lung or pleural disease.
Participants were classified as non-smokers (less than 20 lifetime packs of cigarettes and no cigarettes in the last three months; eight patients); ex-smoker (more than 20 lifetime packs and no cigarettes in the last three months; 40 patients), and current smokers (smoked within the last three months; 11 patients). In one patient exposure to tobacco occurred through lifelong sniffing.

\section{RESPIRATORY FUNCTION TESTS}

Patients underwent measurements of spirometry using a dry cylinder spirometer (P K Morgan), single breath carbon monoxide diffusing capacity using an Auto-Link transfer factor machine (P K Morgan), and lung volumes using a computerised constant volume plethysmograph (P K Morgan). Predicted values were calculated for age, sex, and height ${ }^{11}$ and results were expressed as percentages of predicted values.

\section{CT SCANNING}

All HRCT scans were carried out using an Elscint 2002 scanner with a scanning time of $5.5 \mathrm{~s}$. Sections of $3 \mathrm{~mm}, 10 \mathrm{~mm}$ apart, were obtained from the lung apices to the bases in full inspiration. The mean CT window was 1600 Hounsfield units (range 14601733). Further sections in the prone position were obtained at the lung bases to make certain that any posterior intrapulmonary density was not due to

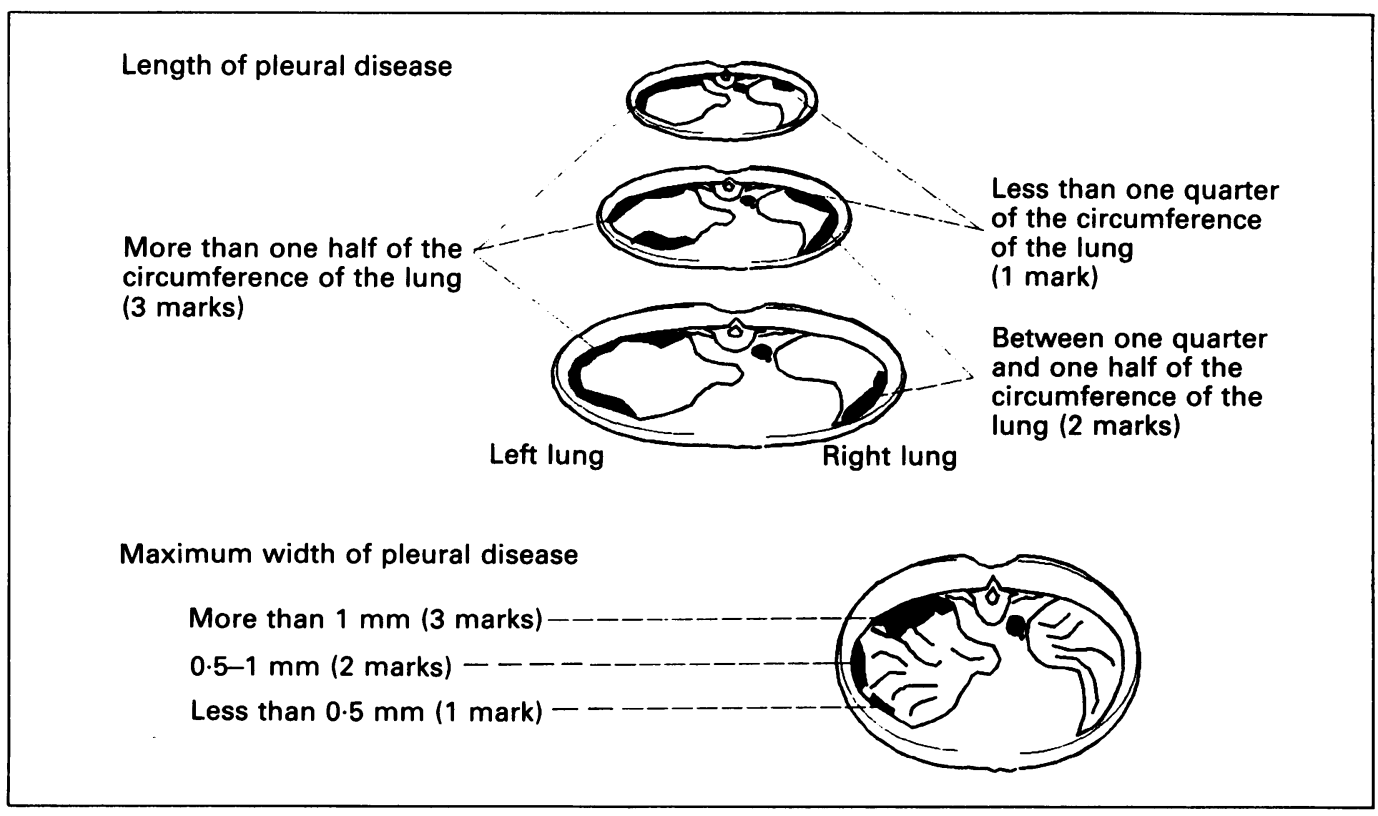

Figure 1 The scoring system for pleural disease on HRCT. The proportion of the lung circumference (excluding the mediastinum) involved by pleural disease was estimated for each lung third. The figures representing the maximum width score were chosen because the scale of the images on HRCT slices was 1/10 that on the chest radiograph. The lung score for each third = length score $\times$ width score. The total HRCT score for each lung is the mean score for the three zones. The final score $=$ left lung score + right lung score. 
gravity induced vascular shadowing. If the shadowing persisted in the prone position it was always regarded as pathological. The full protocol has been described by Strickland and colleagues. ${ }^{7}$

\section{THE SCORING SYSTEM}

All chest radiographs and HRCT scans were assessed by two independent readers unacquainted with the diagnosis. Each lung was divided into upper, middle, and lower thirds from lung apex to the level of the costal insertion of the diaphragm. Eight sections representative of each lung third were selected (a total of 24 HRCT slices per patient).

Pleural disease was assessed on HRCT in each third using a method analogous to the ILO classification of pleural disease on the chest radiograph taking into account the extent and width of the pleural disease. Figures representing different grades of the maximum thickening of pleural disease on HRCT were selected because the scale of the HRCT image compared with that of the chest radiograph was $1 / 10$. Figure 1 illustrates in detail the HRCT scoring system for pleural disease.

Lung fibrosis in each third was assessed using a 12 point scoring system based on the ILO score for the chest radiograph ${ }^{3}$ Emphysema in each lung was also assessed using a 12 point scale analogous to that used to score the interstitial fibrosis. Figures 3, 4, and 5 illustrate the scoring systems for lung fibrosis and emphysema.

On the chest radiograph pleural and parenchymal disease were scored using the ILO method (fig 2). Emphysema was also scored with a 12 point system analogous to the method of scoring of parenchymal fibrosis.

Pleural disease, lung fibrosis, and emphysema in 26 patients were scored on HRCT and the chest radiograph by the two readers on two separate occasions to assess intraobserver agreement.

Scores for patients for each disease were assessed by taking the mean first reading by the two examiners for each disease and were divided into four grades: $(0)$ no disease (score 0-6 for emphysema and fibrosis and 0 for pleural disease), (1) minor disease (score 6-18 for fibrosis and emphysema and 1-6 for pleural disease), (2) moderate disease (score 19-30 for emphysema and fibrosis and 6-12 for pleural disease), and (3) advanced disease (score more than 30 for fibrosis and emphysema and more than 12 for pleural disease). Figure 5 shows example scores by HRCT.

The agreements between the two observers for all lung thirds and between the two readings for each observer for the lung thirds in 26 patients on both CT scan and chest radiograph were assessed. The readings by each observer for each third for fibrosis and emphysema and for each lung for pleural disease were plotted against the reading of the other observer, a method similar to that reported by Liddle $^{12}$ and Mcleod et al. ${ }^{13}$ In theory, if there were no disagreement between the two readers or the two readings for each reader all points would be situated on the central diagonal line starting from $0 / 0$ and

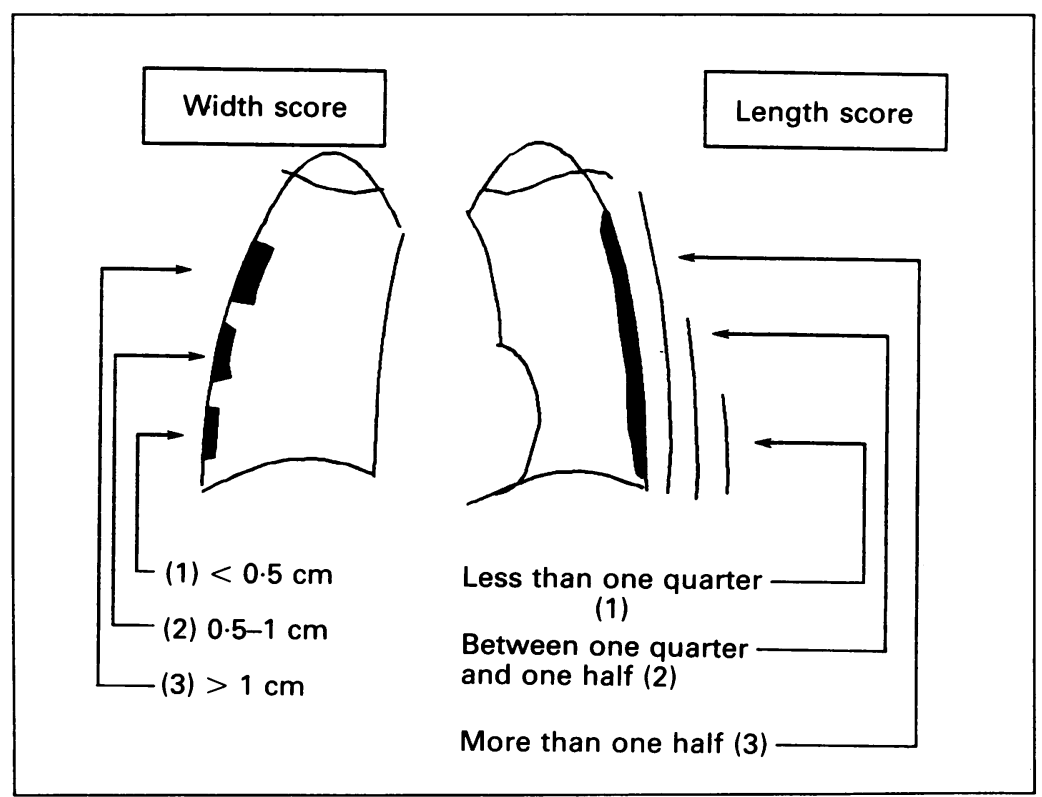

Figure 2 The scoring system for pleural disease on the chest radiograph. The score for each lung $=$ length score $\times$ width score. The final score $=$ left lung score + right lung score. 


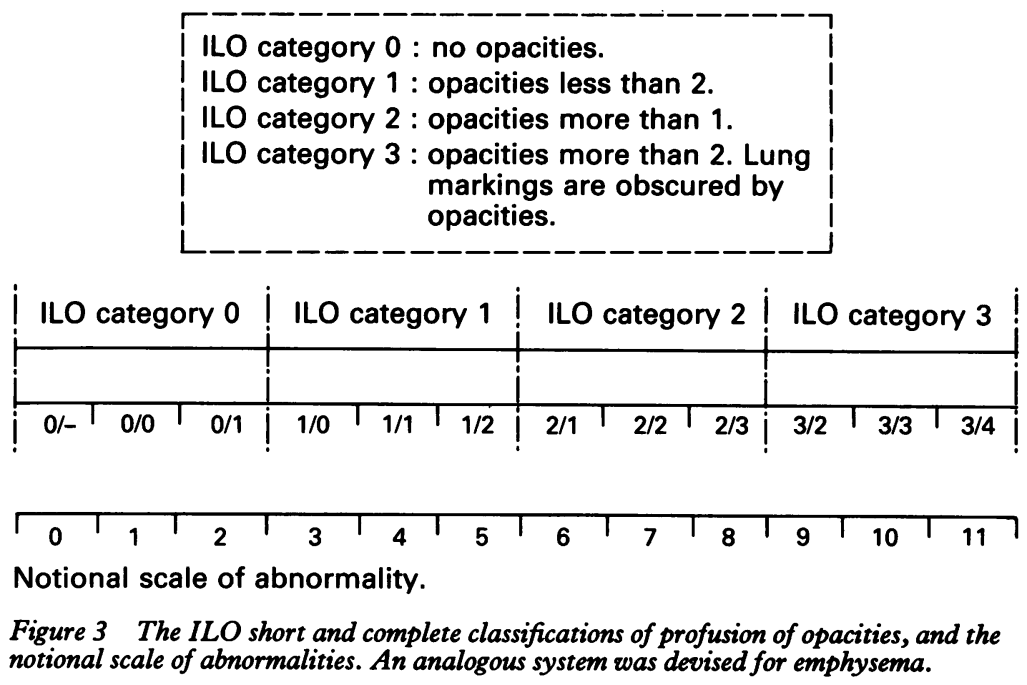

extending to $11 / 11$. The greater the disagreement the further the point would be situated from that line. Figures 6 and 7 explain this method further.

Good agreement was considered to be present when the difference of points between the two observers or between two readings by one observer was $\leqslant 2$.

\section{STATISTICAL ANALYSIS}

Tests for significance for the difference in proportions of HRCT and the chest radiograph scores showing abnormality were based on exact cumulative binomial probabilities.

Multiple regression analyses were performed with the Statgraphic STSC computer package. A forward stepwise selection procedure was adopted and separate methods were constructed for each lung function measurement taking pleural disease, emphysema, and fibrosis scores from HRCT and chest radiograph as explanatory variables. Values of the square of the multiple regression coefficient $r^{2}$ were tabulated to indicated the proportion of the total variation in each lung function variable accounted for by the regression.

\section{Results}

Table 2 shows the scores for pleural disease, emphysema, and lung fibrosis on chest radiograph

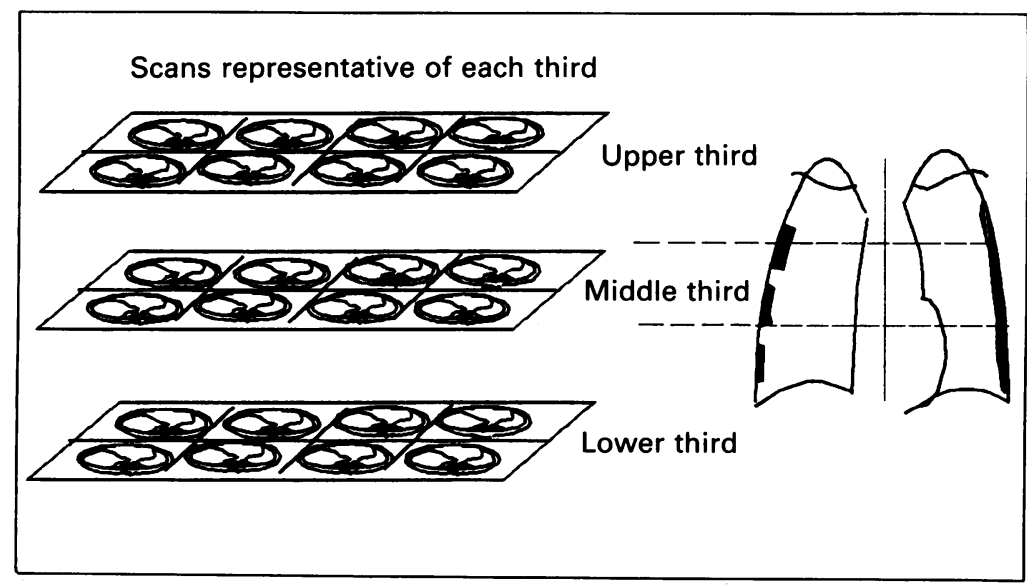

Figure 4 The HRCT and scoring systems for lung fibrosis and emphysema. The score for each third was estimated on eight sections representative for the third. The total score for each lung = the sum of the scores of the three zones. The final score = left lung score + right lung score. 
Table 2 Pleural disease $(P)$, emphysema $(E)$, and fibrosis $(F)$ scores and lung function measurements. Lung functions are expressed as percentage of predicted ${ }^{11}$

\begin{tabular}{|c|c|c|c|c|c|c|c|c|c|c|c|c|c|c|}
\hline \multirow[b]{2}{*}{ No } & \multicolumn{3}{|c|}{ HRCT score } & \multicolumn{3}{|c|}{ Chest radiograph score } & \multirow[b]{2}{*}{$F E V_{1}$} & \multirow[b]{2}{*}{$F V C$} & \multirow[b]{2}{*}{$F E V_{1} / F V C$} & \multirow[b]{2}{*}{$T L C$} & \multirow[b]{2}{*}{$R V$} & \multirow[b]{2}{*}{$T_{L} C O$} & \multirow[b]{2}{*}{$V a$} & \\
\hline & $P$ & $E$ & $F$ & $P$ & $E$ & $F$ & & & & & & & & $\mathrm{KCO}$ \\
\hline 1 & $7 \cdot 0$ & $30 \cdot 8$ & 15.0 & 8.0 & $8 \cdot 0$ & 11.0 & 65 & 100 & 65 & 104 & 104 & 66 & 105 & 68 \\
\hline 2 & 7.0 & 8.5 & 9.5 & 5.0 & $28 \cdot 5$ & 2.5 & 100 & 110 & 91 & 110 & 93 & 59 & 112 & 57 \\
\hline 3 & $7 \cdot 0$ & 9.5 & $50 \cdot 5$ & 1.0 & 6.0 & 62.5 & 58 & 50 & 116 & 58 & 82 & 28 & 54 & 55 \\
\hline 4 & $15 \cdot 0$ & $10 \cdot 3$ & 18.8 & $12 \cdot 0$ & $7 \cdot 0$ & $27 \cdot 5$ & 85 & 78 & 109 & 76 & 82 & 65 & 76 & 94 \\
\hline 5 & 2.0 & 33.0 & $11 \cdot 8$ & 6.0 & $15 \cdot 0$ & $10 \cdot 0$ & 63 & 63 & 100 & 82 & 108 & 31 & 66 & 53 \\
\hline 6 & 14.0 & 18.5 & 55.5 & 8.0 & 6.0 & 51.0 & 39 & 47 & 83 & 55 & 75 & 62 & 48 & 72 \\
\hline 7 & $4 \cdot 0$ & 63.0 & $46 \cdot 0$ & 3.0 & 37.5 & 50.5 & 41 & 49 & 84 & 87 & 87 & 34 & 65 & 52 \\
\hline 8 & $6 \cdot 0$ & 34.5 & $17 \cdot 8$ & 6.0 & 21.5 & 21.5 & 74 & 91 & 81 & 82 & 95 & 36 & 82 & 48 \\
\hline 9 & $3 \cdot 0$ & $17 \cdot 8$ & $20 \cdot 5$ & $2 \cdot 0$ & $11 \cdot 0$ & $10 \cdot 5$ & 91 & 99 & 92 & 92 & 81 & 80 & 99 & 89 \\
\hline 10 & 13.0 & $35 \cdot 3$ & $12 \cdot 8$ & $6 \cdot 0$ & $25 \cdot 5$ & 10.5 & 39 & 80 & 49 & 112 & 149 & 71 & 86 & 91 \\
\hline 11 & 11.0 & 23.5 & $20 \cdot 0$ & 0.0 & 10.0 & $17 \cdot 0$ & 100 & 100 & 100 & 110 & 123 & 82 & 113 & 80 \\
\hline 12 & 13.0 & $10 \cdot 3$ & $30 \cdot 5$ & $6 \cdot 0$ & $10 \cdot 5$ & 27.5 & 71 & 72 & 99 & 71 & 71 & 54 & 59 & 89 \\
\hline 13 & 13.0 & 23.0 & $19 \cdot 3$ & 6.0 & 6.0 & 12.5 & 60 & 83 & 72 & 93 & 99 & 78 & 86 & 101 \\
\hline 14 & 0.0 & $38 \cdot 0$ & $8 \cdot 3$ & 0.0 & $29 \cdot 0$ & $7 \cdot 0$ & 93 & 129 & 72 & 139 & 127 & 65 & 145 & 47 \\
\hline 15 & $12 \cdot 0$ & $9 \cdot 3$ & 17.5 & $12 \cdot 0$ & 11.0 & 12.5 & 103 & 73 & 141 & 87 & 101 & 45 & 109 & 40 \\
\hline 16 & 16.0 & $14 \cdot 8$ & 14.0 & $9 \cdot 0$ & $17 \cdot 0$ & 20.5 & 96 & 108 & 89 & 98 & 82 & 59 & 97 & 61 \\
\hline 17 & $2 \cdot 0$ & $25 \cdot 8$ & $20 \cdot 0$ & 0.0 & $16 \cdot 0$ & 13.5 & 96 & 103 & 93 & 115 & 102 & 54 & 102 & 53 \\
\hline 18 & $12 \cdot 0$ & $19 \cdot 3$ & 15.0 & 3.0 & $27 \cdot 0$ & 9.5 & 62 & 85 & 73 & 78 & 71 & 78 & 88 & 89 \\
\hline 19 & $18 \cdot 0$ & $6 \cdot 0$ & 18.0 & 18.0 & 6.0 & 13.5 & 65 & 50 & 130 & 61 & 87 & 61 & 64 & 95 \\
\hline 20 & $8 \cdot 0$ & $8 \cdot 0$ & $15 \cdot 8$ & 8.0 & $10 \cdot 5$ & 9.5 & 119 & 119 & 100 & 111 & 101 & 95 & 101 & 90 \\
\hline 21 & 13.0 & $24 \cdot 8$ & $15 \cdot 3$ & $12 \cdot 0$ & 23.5 & $17 \cdot 0$ & 42 & 64 & 66 & 95 & 135 & 83 & 85 & 98 \\
\hline 22 & 7.0 & 15.0 & $17 \cdot 0$ & $2 \cdot 0$ & $17 \cdot 0$ & 8.0 & 106 & 104 & 102 & 113 & 124 & 96 & 109 & 87 \\
\hline 23 & $10 \cdot 0$ & $24 \cdot 3$ & $10 \cdot 0$ & $10 \cdot 0$ & 26.5 & 11.5 & 64 & 66 & 97 & 80 & 111 & 60 & 88 & 68 \\
\hline 24 & 14.0 & $14 \cdot 3$ & 16.0 & $8 \cdot 0$ & 6.0 & $18 \cdot 0$ & 73 & 69 & 106 & 66 & 53 & 75 & 73 & 107 \\
\hline 25 & $12 \cdot 0$ & 15.0 & 11.0 & $4 \cdot 0$ & $10 \cdot 0$ & 11.5 & 89 & 83 & 107 & 85 & 86 & 84 & 90 & 100 \\
\hline 26 & 13.0 & $35 \cdot 3$ & 35.5 & $2 \cdot 0$ & 6.0 & $35 \cdot 5$ & 74 & 69 & 107 & 86 & 114 & 47 & 72 & 71 \\
\hline 27 & $9 \cdot 0$ & $17 \cdot 0$ & 6.0 & 5.0 & 6.0 & 6.0 & 102 & 96 & 110 & 94 & 103 & 92 & 92 & 105 \\
\hline 28 & 9.0 & $24 \cdot 0$ & $17 \cdot 0$ & 8.0 & 13.0 & $10 \cdot 0$ & 98 & 87 & 118 & 85 & 106 & 70 & 90 & 88 \\
\hline 29 & 9.0 & 33.0 & $7 \cdot 0$ & 3.0 & 11.0 & $9 \cdot 0$ & 83 & 86 & 103 & 127 & 168 & 84 & 106 & 89 \\
\hline 30 & 7.0 & $11 \cdot 0$ & $6 \cdot 0$ & $7 \cdot 0$ & 6.0 & $6 \cdot 0$ & 94 & 111 & 81 & 107 & 100 & 108 & 95 & 115 \\
\hline 31 & 6.0 & $12 \cdot 0$ & $6 \cdot 0$ & $8 \cdot 0$ & $7 \cdot 0$ & $6 \cdot 0$ & 85 & 82 & 110 & 65 & 61 & 86 & 82 & 115 \\
\hline 32 & $17 \cdot 0$ & $22 \cdot 0$ & $8 \cdot 0$ & $17 \cdot 0$ & $10 \cdot 0$ & $11 \cdot 0$ & 76 & 76 & 100 & 85 & 101 & 91 & 85 & 107 \\
\hline 33 & 14.0 & 15.0 & 13.0 & $17 \cdot 0$ & 14.0 & 14.0 & 34 & 44 & 83 & 83 & 160 & 76 & 59 & 141 \\
\hline 34 & 4.0 & 18.0 & $7 \cdot 0$ & $1 \cdot 0$ & $10 \cdot 0$ & 9.0 & 98 & 109 & 90 & 105 & 89 & 105 & 94 & 102 \\
\hline 35 & 6.0 & $9 \cdot 0$ & 6.0 & $4 \cdot 0$ & $9 \cdot 0$ & $6 \cdot 0$ & 107 & 94 & 109 & 89 & 97 & 113 & 91 & 122 \\
\hline 36 & 3.0 & $29 \cdot 0$ & 6.0 & $10 \cdot 0$ & $11 \cdot 0$ & $9 \cdot 0$ & 55 & 70 & 83 & 107 & 200 & 97 & 85 & 124 \\
\hline 37 & 6.0 & 12.0 & $7 \cdot 0$ & $1 \cdot 0$ & 6.0 & 6.0 & 90 & 92 & 91 & 92 & 96 & 98 & 86 & 113 \\
\hline 38 & 6.0 & 19.0 & $6 \cdot 0$ & $4 \cdot 0$ & $7 \cdot 0$ & $7 \cdot 0$ & 111 & 106 & 111 & 99 & 81 & 104 & 98 & 115 \\
\hline 39 & 13.0 & $17 \cdot 0$ & $8 \cdot 0$ & 6.0 & $12 \cdot 0$ & $7 \cdot 0$ & 99 & 95 & 111 & 96 & 106 & 100 & 92 & 119 \\
\hline 40 & $12 \cdot 0$ & $11 \cdot 0$ & $10 \cdot 0$ & $11 \cdot 0$ & $12 \cdot 0$ & 8.0 & 95 & 99 & 90 & - & - & 76 & 78 & 94 \\
\hline 41 & 5.0 & $30 \cdot 0$ & $7 \cdot 0$ & $1 \cdot 0$ & $7 \cdot 0$ & 6.0 & 120 & 113 & 112 & 104 & 82 & 104 & 106 & 106 \\
\hline 42 & 1.0 & 15.0 & $6 \cdot 0$ & 0.0 & 6.0 & 6.0 & 120 & 125 & 102 & 125 & 111 & 101 & 111 & 89 \\
\hline 43 & 6.0 & $12 \cdot 0$ & $7 \cdot 0$ & 3.0 & 6.0 & $6 \cdot 0$ & 78 & 84 & 93 & 100 & 103 & 81 & 89 & 91 \\
\hline 44 & $6 \cdot 0$ & 13.0 & 6.0 & $1 \cdot 0$ & $7 \cdot 0$ & 8.0 & 114 & 106 & 112 & 108 & 115 & 103 & 98 & 111 \\
\hline 45 & $7 \cdot 0$ & 18.0 & 6.0 & $8 \cdot 0$ & $12 \cdot 0$ & 9.0 & 71 & 80 & 83 & 99 & 140 & 75 & 85 & 90 \\
\hline 46 & 5.0 & $10 \cdot 0$ & $6 \cdot 0$ & $11 \cdot 0$ & 6.0 & 6.0 & 79 & 80 & 104 & 120 & 181 & 91 & 83 & 121 \\
\hline 47 & $10 \cdot 0$ & 14.0 & $10 \cdot 0$ & 3.0 & $9 \cdot 0$ & $9 \cdot 0$ & 84 & 89 & 99 & 85 & 63 & 74 & 89 & 89 \\
\hline 48 & 15.0 & $24 \cdot 0$ & $10 \cdot 0$ & $10 \cdot 0$ & $13 \cdot 0$ & 15.0 & 29 & 54 & 56 & 148 & 200 & 70 & 81 & 96 \\
\hline 49 & 14.0 & $34 \cdot 0$ & $21 \cdot 0$ & $5 \cdot 0$ & $22 \cdot 0$ & $27 \cdot 0$ & 37 & 58 & 67 & 104 & 185 & 61 & 60 & 88 \\
\hline 50 & 8.0 & $31 \cdot 0$ & 6.0 & $2 \cdot 0$ & $27 \cdot 0$ & $11 \cdot 0$ & 103 & 104 & 101 & 115 & 140 & 90 & 114 & 83 \\
\hline 51 & $12 \cdot 0$ & $17 \cdot 0$ & $7 \cdot 0$ & $11 \cdot 0$ & 8.0 & $7 \cdot 0$ & 87 & 91 & 100 & 93 & 104 & 76 & 60 & 94 \\
\hline 52 & 9.0 & $27 \cdot 0$ & 6.0 & 6.0 & $20 \cdot 0$ & $10 \cdot 0$ & 99 & 107 & 92 & - & - & 110 & 86 & 128 \\
\hline 53 & 6.0 & $16 \cdot 0$ & $8 \cdot 0$ & $4 \cdot 0$ & $9 \cdot 0$ & $7 \cdot 0$ & 92 & 99 & 98 & - & - & 70 & 89 & 88 \\
\hline 54 & $5 \cdot 0$ & 23.0 & $8 \cdot 0$ & $4 \cdot 0$ & 6.0 & $24 \cdot 0$ & 90 & 90 & 100 & - & - & 88 & 100 & 128 \\
\hline 55 & $12 \cdot 0$ & $31 \cdot 0$ & $12 \cdot 0$ & $14 \cdot 0$ & $10 \cdot 0$ & $9 \cdot 0$ & 34 & 57 & 59 & 99 & 142 & 86 & 79 & 108 \\
\hline 56 & $4 \cdot 0$ & $12 \cdot 0$ & 6.0 & $5 \cdot 0$ & 6.0 & $8 \cdot 0$ & 107 & 109 & 98 & 108 & 104 & - & - & - \\
\hline 57 & $5 \cdot 0$ & $11 \cdot 0$ & 6.0 & 1.0 & $6 \cdot 0$ & $8 \cdot 0$ & 133 & 86 & 102 & 93 & 121 & 105 & 89 & 127 \\
\hline 58 & $8 \cdot 0$ & $38 \cdot 0$ & 8.0 & $7 \cdot 0$ & $29 \cdot 0$ & $10 \cdot 0$ & 61 & 88 & 72 & - & - & 58 & 98 & 63 \\
\hline 59 & $10 \cdot 0$ & 10.0 & 6.0 & 9.0 & 6.0 & $9 \cdot 0$ & 73 & 88 & 90 & - & - & 111 & 96 & 127 \\
\hline 60 & $2 \cdot 0$ & $19 \cdot 0$ & 13.0 & 0.0 & $6 \cdot 0$ & $12 \cdot 0$ & 87 & 91 & 100 & 115 & 149 & 88 & 115 & 81 \\
\hline & & & & & & & Mean (S & D) & & & & & & \\
\hline & $8 \cdot 0$ & $18 \cdot 0$ & $10 \cdot 0$ & $5 \cdot 0$ & $10 \cdot 0$ & $9 \cdot 0$ & $82(25)$ & $87(20)$ & $94(17)$ & $\begin{array}{c}97 \\
(19)\end{array}$ & $\begin{array}{l}112 \\
(34)\end{array}$ & $\begin{array}{r}78 \\
(21)\end{array}$ & $\begin{array}{r}89 \\
(18)\end{array}$ & $\begin{array}{r}92 \\
(24)\end{array}$ \\
\hline
\end{tabular}

$\mathrm{FEV}_{1}=$ Forced expiratory volume in one second; FVC $=$ forced vital capacity; TLC $=$ total lung capacity; RV = residual volume $\mathrm{TLCO}_{\mathrm{L}}=$ carbon monoxide transfer factor; $\mathrm{V}_{\mathrm{a}}=$ alveolar volume; $\mathrm{KCO}=$ transfer coefficient. 

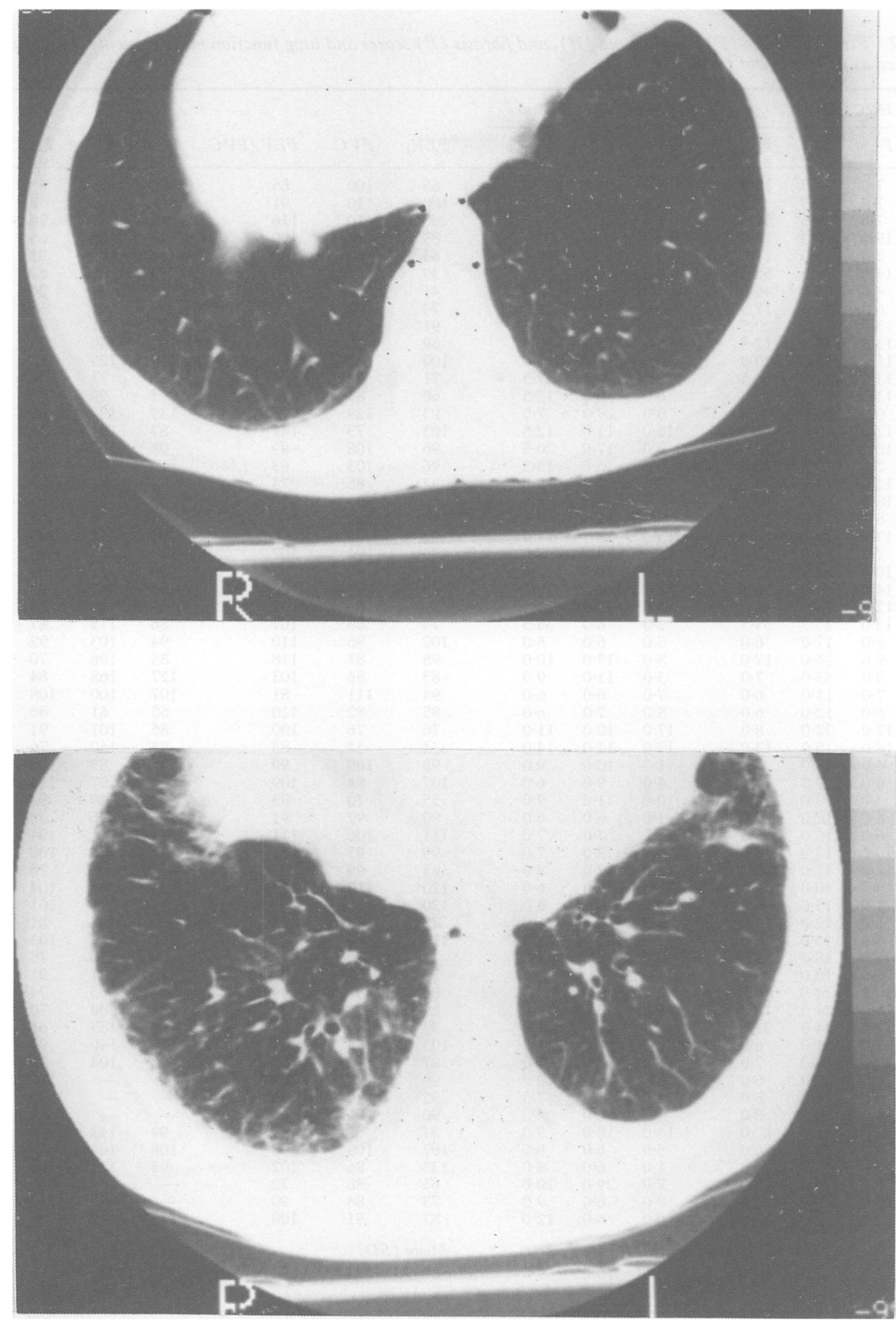

Figure 5 Examples for HRCT score. Upper left-Left lung: grade 1 for emphysema and grade 0 for fibrosis. Right lung: grade 1 for emphysema and grade 1 for fibrosis. Lower left-Left lung: grade 2 for emphysema and grade 1 for fibrosis. Right lung: grade 2 for emphysema and grade 2 for fibrosis. Upper right-Left lung: grade 2 for emphysema and grade 2/3 for fibrosis. Right lung: grade 1 for emphysema and grade 3/ + for fibrosis. Lower right - Left lung:grade 3 for emphysema and grade 2 for fibrosis. right lung: grade 3 for emphysema and for fibrosis. 

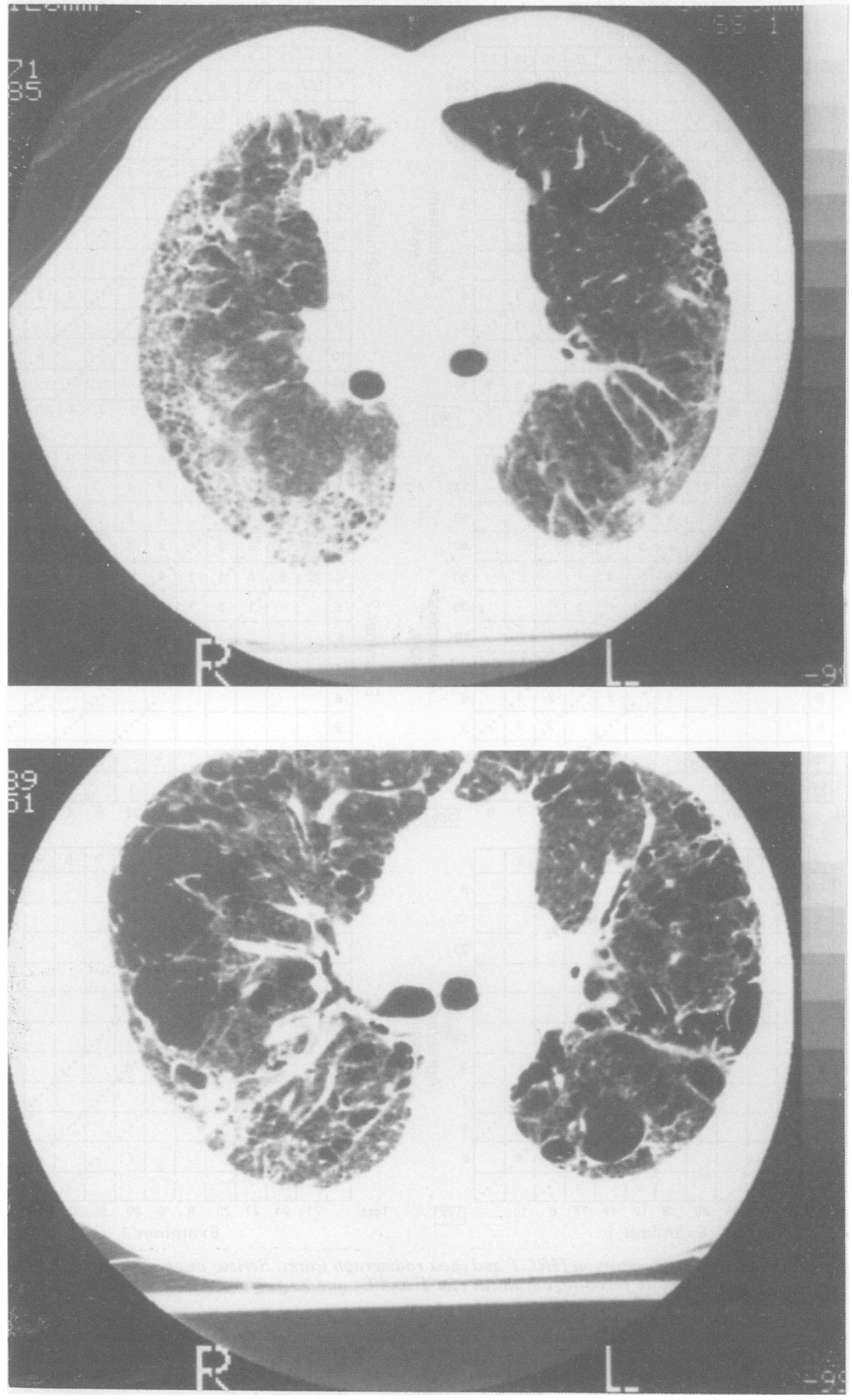

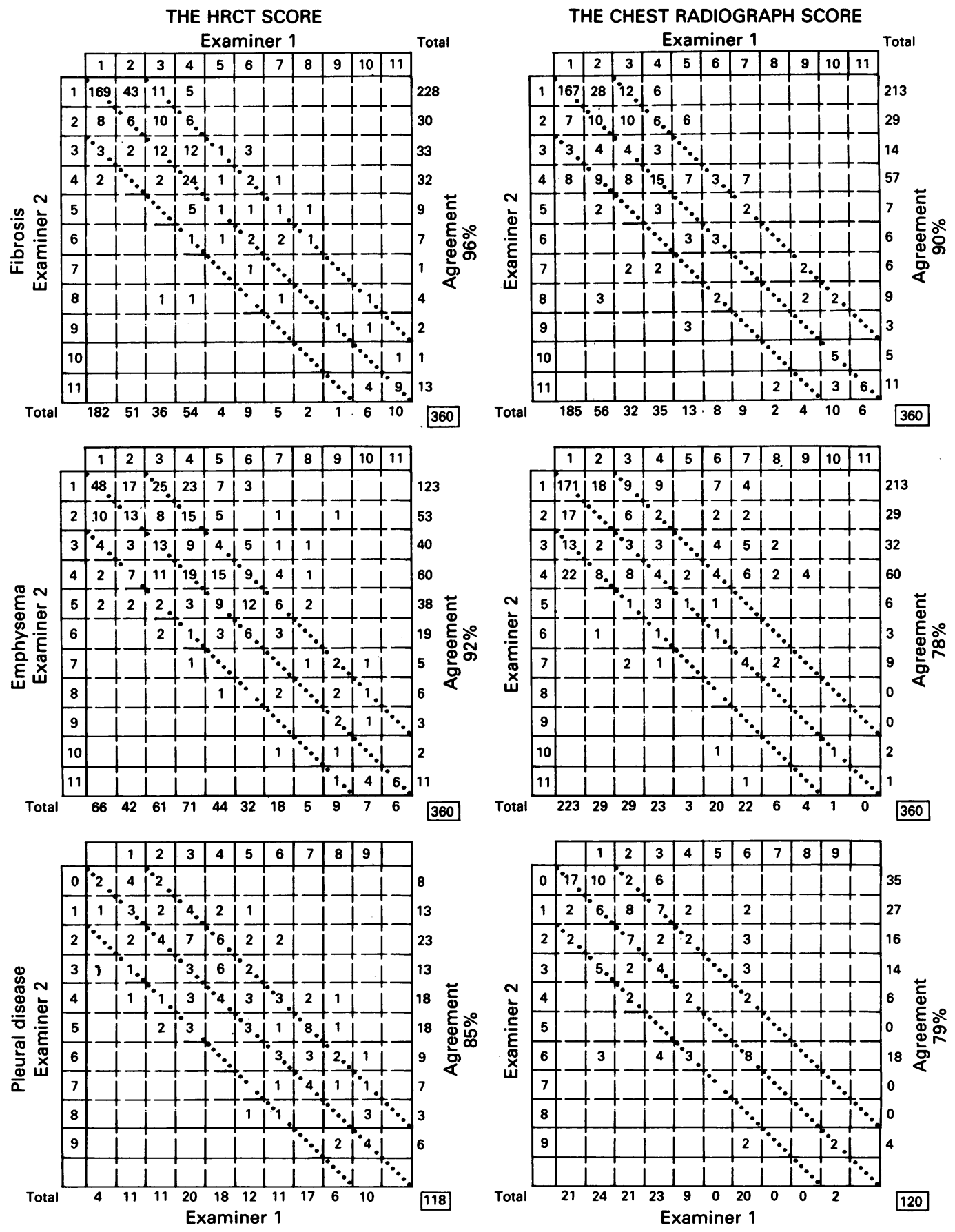

Figure 6 The interobserver agreement on HRCT and chest radiograph scores. Serious disagreement lies outside the diagonal lines. Agreement refers to percentage of thirds (for $F$ and $E$ ) and lungs (for $P$ ) in which the difference in score was $\leqslant 2$. 

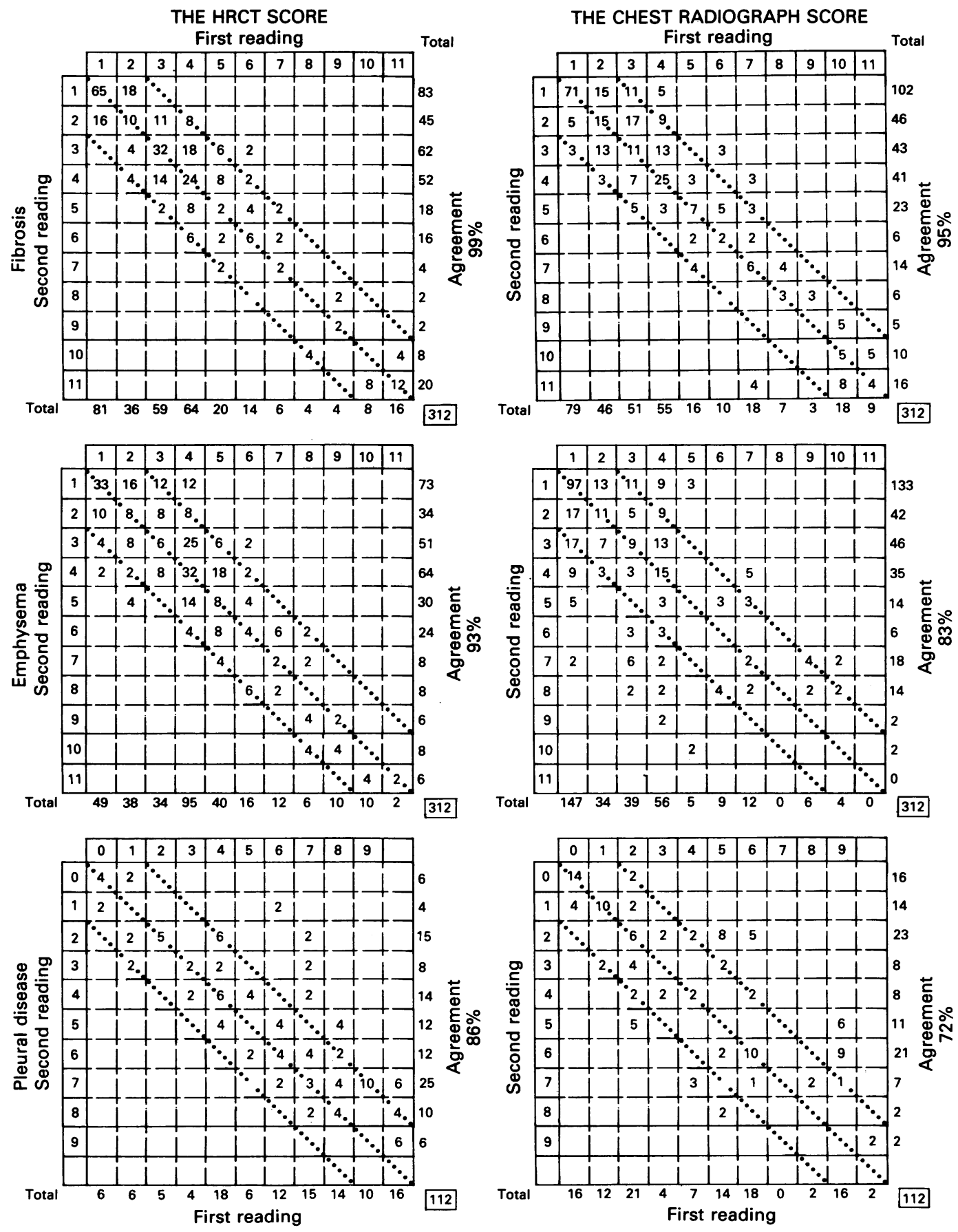

Figure 7 The intraobserver agreement on the first and second readings by the two examiners for HRCT and chest radiograph scores for lung fibrosis, emphysema, and pleural disease (26 patients). Serious disagreement lies outside the diagnonal lines. Agreement refers to percentage of thirds (for $F$ and $E$ ) and for lungs (for $P$ ) in which the difference in score was $\leqslant 2$. 
Table 3 Number of patients in whom the different grades ${ }^{\star}$ of severity of each disorder was estimated by the HRCT score or the chest radiograph score (CXR) as assessed by mean reading of the two observers. The diagonal line refers to number of patients in whom degrees of severity was assessed equally by HRCT and CXR. Figures below this line represent patients in whom the HRCT score was higher than $C X R$ score and vice versa

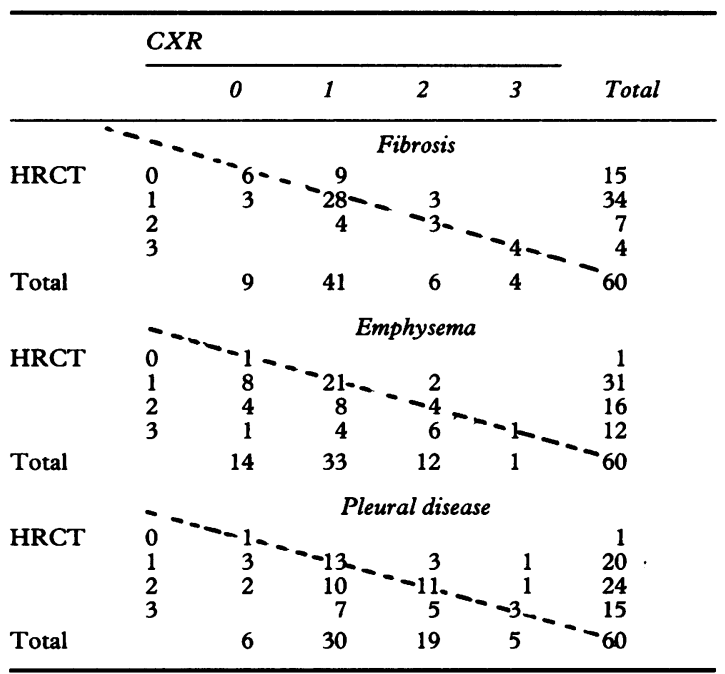

* Grade 0 (score $0-6$ for $F$ and $E$ and 0 for $P$ ).

Grade 1 (score 7-18 for $F$ and $E$ and $1-6$ for $P$ ).

Grade 2 (score $19-30$ for $F$ and $E$ and $7-12$ for $P$ )

Grade 3 (score $31-66$ for $F$ and $E$ and $13-18$ for $P$ ).

and on HRCT scan, and lung function results expressed as percentages of predicted values.

Table 3 shows the grades allocated to each type of disorder on HRCT and chest radiograph. Table 4 shows the frequency of detection of each type of disorder by each technique. Emphysema and pleural disease were assessed as being more advanced and were detected more frequently by HRCT than by chest radiograph whereas there was no significant difference between the techniques in frequency of detection and assessment of severity of fibrosis. The chest radiograph was interpreted as suggesting lung fibrosis in nine patients in whom HRCT showed no lung fibrosis whereas the reverse occurred in three patients.

Good interobserver agreement (difference $\leqslant 2$ points) on the HRCT scores was achieved in $96 \%$, $92 \%$, and $85 \%$ compared with $90 \%, 78 \%$, and $79 \%$ for the chest radiograph for fibrosis, emphysema, and pleural disease respectively.

Intraobserver agreement for all diseases was better on the HRCT score than on the chest radiograph score. Figures 6 and 7 give detailed results for inter and intraobserver agreements.

Table 5 shows the results of multiple regression analysis of lung functions in relation to lung fibrosis,
Table 4 Number of patients in whom a disease was not detected (-) ( 0 grade) or was detected $(+)$ (grade $>0)$ by $C X R$ and $H R C T$

\begin{tabular}{llccl}
\hline & \multicolumn{3}{c}{$C X R$} & \multirow{2}{l}{ p Value } \\
\cline { 3 - 5 } & & $(-)$ & $(+)$ & Fibrosis \\
HRCT & $(-)$ & 6 & 9 & NS \\
& $(+)$ & 3 & 42 & \\
HRCT & $(-)$ & 1 & Emphysema & \\
& $(+)$ & 13 & 46 & $<0.0002$ \\
HRCT & $(-)$ & 1 & 0 & \\
& $(+)$ & 5 & 54 & 0.06 \\
\hline
\end{tabular}

emphysema, and pleural disease on HRCT and chest radiograph. The model chosen for each measurement of lung function was the one achieving the highest $r^{2}$ value. Chest radiograph scores and HRCT explained variance in lung function results to a similar extent.

\section{Discussion}

The ILO method of scoring the plain chest radiograph is well established; HRCT is more sensitive than the chest radiograph in assessing pleural disease, ${ }^{1415}$ pulmonary disease, ${ }^{6816}$ and emphysema.$^{69}$ In one study, ${ }^{6}$ evidence of asbestosis was found on HRCT in $34 \%$ of 169 cases in whom the chest radiograph was scored less than $1 / 0$ on the ILO scale. A scoring system for pulmonary asbestosis on HRCT has not, however, been described.

We have previously shown that in asbestos workers with no evidence of asbestosis HRCT assesses the extent of pleural disease better than the plain radiograph, and we showed an inverse correlation between the extent of pleural disease and all lung function measurements except the transfer coefficient. ${ }^{17}$ In another study, the extent of pulmonary disease on the chest radiograph in patients with asbestosis inversely correlated with lung volumes. ${ }^{4}$ In both studies, however, the extent of emphysema was not taken into account. Previous methods for scoring emphysema on CT scan have been shown to correlate well with pathological scores and with lung function. ${ }^{98-20}$ In these studies, patients did not have any parenchymal fibrosis or pleural disease, which can interact with the morphological aspects and functional consequences of emphysema.

In the current study a 12 point scoring system analogous to the ILO method of scoring the chest radiograph was used to assess the extent of interstitial fibrosis and emphysema on HRCT. Pleural disease on HRCT was also scored using a system based on the ILO system for the chest radiograph. Minimal degrees of emphysema and pleural diseases were detected by the HRCT more often than on the chest 
Table 5 Summary of optimal regression models of each lung function test on HRCT and chest radiograph scores for interstitial fibrosis $(F)$, emphysema $(E)$, and pleural disease $(P)$

\begin{tabular}{|c|c|c|c|c|c|c|c|}
\hline \multicolumn{4}{|c|}{ Models based on plain score } & \multicolumn{4}{|c|}{ Models based on HRCT score } \\
\hline $\begin{array}{l}\text { Lung function } \\
\text { (\% predicted) }\end{array}$ & $\begin{array}{l}\text { Standardised } \\
\text { coefficient }{ }^{\star}\end{array}$ & p Value & $r^{2}$ & & $\begin{array}{l}\text { Standardised } \\
\text { coefficient }\end{array}$ & p Value & $r^{2}$ \\
\hline $\begin{array}{c}\mathbf{F E V}_{1}: \\
\mathbf{P} \\
\mathbf{E} \\
\mathbf{F}\end{array}$ & $\begin{array}{l}-2.3 \\
-1.0 \\
-0.5\end{array}$ & $\begin{array}{l}<0.0002 \\
<0.0002 \\
<0.03\end{array}$ & 0.48 & $\begin{array}{l}\mathbf{P} \\
\mathbf{F} \\
\mathbf{E}\end{array}$ & $\begin{array}{l}-2.8 \\
-0.9 \\
-0.9\end{array}$ & $\begin{array}{l}<0.00001 \\
<0.00001 \\
<0.007\end{array}$ & 0.50 \\
\hline $\begin{array}{l}\text { FVC: } \\
\text { P } \\
\mathbf{F} \\
(\mathbf{E}) \dagger\end{array}$ & $\begin{array}{l}-1.9 \\
-0.8 \\
(-0.3)\end{array}$ & $\begin{array}{l}<0.0003 \\
<0.0005 \\
\text { NS }\end{array}$ & $0 \cdot 42$ & $\begin{array}{l}\mathbf{P} \\
\mathbf{F} \\
(\mathbf{E})\end{array}$ & $\begin{array}{l}-2.3 \\
-1.0 \\
-0.03\end{array}$ & $\begin{array}{l}<0.0001 \\
<0.0001 \\
\text { NS }\end{array}$ & 0.54 \\
\hline $\begin{array}{c}\text { TLC: } \\
\mathbf{P} \\
\mathbf{E} \\
\mathbf{F}\end{array}$ & $\begin{array}{l}-1.0 \\
+0.6 \\
-0.9\end{array}$ & $\begin{array}{l}<0.04 \\
<0.004 \\
<0.00001\end{array}$ & 0.43 & $\begin{array}{l}\mathbf{P} \\
\mathbf{F} \\
\mathbf{E}\end{array}$ & $\begin{array}{l}-1.2 \\
+0.6 \\
-0.9\end{array}$ & $\begin{array}{l}<0.02 \\
<0.03 \\
<0.0001\end{array}$ & 0.43 \\
\hline $\begin{array}{l}\text { RV: } \\
\mathbf{E} \\
\mathbf{F} \\
(\mathbf{P})\end{array}$ & $\begin{array}{l}+1.3 \\
-1.1 \\
+0.7\end{array}$ & $\begin{array}{l}<0.005 \\
<0.009 \\
\text { NS }\end{array}$ & $0 \cdot 21$ & $\begin{array}{l}(\mathbf{P}) \\
(\mathbf{E}) \\
(\mathbf{F})\end{array}$ & $\begin{array}{l}+1.4 \\
+0.6 \\
-0.9\end{array}$ & $\begin{array}{l}\text { NS } \\
\text { NS } \\
\text { NS }\end{array}$ & $0 \cdot 13$ \\
\hline $\begin{array}{c}\text { TLCO: } \\
\text { F } \\
\text { E } \\
(\mathbf{P})\end{array}$ & $\begin{array}{l}-1.2 \\
-0.5 \\
-0.4\end{array}$ & $\begin{array}{l}<0.0003 \\
<0.0003 \\
\text { NS }\end{array}$ & 0.5 & $\begin{array}{l}\mathbf{F} \\
\mathbf{E} \\
(\mathbf{P})\end{array}$ & $\begin{array}{l}-1.2 \\
-0.8 \\
-0.6\end{array}$ & $\begin{array}{l}<0.00001 \\
<0.0001 \\
\text { NS }\end{array}$ & 0.54 \\
\hline $\begin{array}{l}\text { Va: } \\
\stackrel{\mathbf{P}}{\mathbf{F}} \\
(\mathbf{E})\end{array}$ & $\begin{array}{l}-1.4 \\
-0.7 \\
+0.11\end{array}$ & $\begin{array}{l}<0.0003 \\
<0.0003 \\
\text { NS }\end{array}$ & $0 \cdot 38$ & $\begin{array}{l}\mathbf{P} \\
\mathbf{F} \\
\text { (E) }\end{array}$ & $\begin{array}{l}-1.8 \\
-0.9 \\
+0.4\end{array}$ & $\begin{array}{l}<0.004 \\
<0.0001 \\
\text { NS }\end{array}$ & 0.51 \\
\hline $\begin{array}{c}\text { KCO: } \\
\mathbf{F} \\
\mathbf{E} \\
(\mathbf{P})\end{array}$ & $\begin{array}{l}-0.8 \\
-0.6 \\
+0.9\end{array}$ & $\begin{array}{l}<0.004 \\
<0.004 \\
\text { NS }\end{array}$ & $0 \cdot 25$ & $\begin{array}{l}\mathbf{F} \\
\mathbf{E} \\
(\mathbf{P})\end{array}$ & $\begin{array}{l}-1.4 \\
-0.7 \\
+1.1\end{array}$ & $\begin{array}{l}<0.004 \\
<0.0001 \\
\text { NS }\end{array}$ & 0.34 \\
\hline
\end{tabular}

* Standardised coefficient $=$ change in lung function for a one standard deviation increase in the variable. (the sign indicates the direction of the change).

†Variables in parentheses do not reach $5 \%$ level of significance.

radiograph. For fibrosis, the chest radiograph suggested intestitial fibrosis in nine cases in which HRCT did not. The reason for this may be the presence of pleural disease that caused examiners to report minimal degrees of interstitial fibrosis.

There was good interobserver and intraobserver agreement on scoring the three conditions on HRCT. Previous studies have shown variable results for interobserver and intraobserver agreement on profusion of opacities on chest radiograph using the ILO scoring system. Liddle found that the interobserver agreement on profusion of opacities on 296 chest films was $61.5 \%$ and the average intraobserver agreement was only $44 \% .{ }^{12}$ In a later study the interobserver agreement within a half grade on the ILO score on the profusion of opacities was $71 \% .^{13}$ Unlike the current study, however, the score for pulmonary fibrosis in each lung was considered to be the score of the most severely affected zone. The comparable interobserver agreements within a half grade in our study were $79 \%$ on the plain chest radiograph and $88 \%$ on HRCT (fig 6 ).

Correlations between scores for the various types of disease and lung function results were similar for chest radiograph and HRCT. The explanation of this is probably that the main advantage of HRCT over the plain chest radiograph is in detection of minimal degrees of lung fibrosis, emphysema, and pleural disease that may not contribute significantly to impairent of lung function. When disease is severe enough to significantly affect lung function it is apparent on the chest radiograph.

We conclude that the scoring system for HRCT is reproducible and allows good interoberver agreement. The scores correlate with impairment of lung function. The detection of coexisting emphysema is particularly facilitated by HRCT and this may be helpful in assessing the causes of disability in asbestos workers.

We thank Miss Elizabeth Paul from the epidemiology department at The London Chest Hospital for her assistance in the statistical analysis of the data.

Requests for reprints to: $\operatorname{Dr} \mathrm{R} M$ Rudd, The London Chest Hospital, Bonner Road, London E2 9JX, UK 
1 Becklake MR, Fournier-Massey G, Mcdonald JC, Siemiatycki $\mathrm{J}$, Rossiter C. Lung function in relation to radiographic changes in Quebec asbestos workers. Bull Eur Physiopathol Respir 1970;6:637-43.

2 Becklake MR. Asbestos-related disease of the lung and other organs: their epidemiological implications for clinical practice. Am Rev Respir Dis 1976;114:187-227.

3 International Labour Office/UC. I.ternational classification of radiographs of pneumoconiosis. Geneva: ILO, 1980. (Occupational safety and health series. No 22 ( $\operatorname{rev} 80)$.)

4 Kilburn KH, Warshaw RH. Correlation of pulmonary functional impairment with radiographic asbestosis (ILO category). Am Rev Respir Dis 1989;139:A210.

$5 \mathrm{Katz} D$, Kreel L. Computed tomography in pulmonary asbestosis. Clin Radiol 1979;30:207.

6 Staples CA, Gamsu G, Ray CS, Webb WR. High resolution computed tomography and lung function in asbestos-exposed workers with normal chest radiograph. Am Rev Respir Dis 1989;139:1502-8.

7 Strickland B, Brennan J, Denison DM. Computed tomography in diffuse lung disease: improving the image. Clin Radiol 1986;37:335-8.

8 Lozewicz S, Reznek RH, Herdman M, Dacie JE, McLean A, Davies RJ. Role of computed tomography in evaluation of asbestos related lung disease. $B r J$ Ind Med 1989;46:777-81.

9 Kuwano K, Matsuba K, Ikeda T, Murakami J, Araki A, Nishitani H, et al. The diagnosis of mild emphysema. Correlation of computed tomography and pathology scores. $\mathrm{Am} \mathrm{Rev}$ Respir Dis 1990;141:169-78.

10 Bergin C, Muller NL, Nicholas DM, Lillington G, Hogg JC, Mullen B, et al. The diagnosis of emphysema-a computed tomographic-pathologic correlation. Am Rev Respir Dis 1986;133:541-6.

11 Cotes JE. Lung function: Assessment and application in medicine. 4th ed. Oxford: Blackwell, 1979.
12 Liddle FDK. Radiological assessment of small pneumoconiotic opacities. Br J Ind Med 1977;34:85-94.

13 Mcleod TC, Carrington CB, Gaensler EA. Diffuse interstitial lung disease: a new scheme for description. Radiology 1983;149:353-63.

14 Friedman AC, Fiel SB, Fisher MS, Radecki PD, Lev-Toaff AS, Caroline DF. Asbestos-related pleural disease and asbestosis: a comparison of CT and chest radiography. American Journal of Radiology 1988;150:269-75.

15 Aberle DR, Gamsu G, Ray CS, Feuerstein IM. Asbestos related pleural and parenchymal fibrosis: detection with high resolution CT. Radiology 1988;166:729-43.

16 Yoshimura H, Hatakeyama M, Otsuji H, Maeda M, Ohishi H, Uchida H, et al. Pulmonary asbestosis: A CT study of subpleural curvilinear shadow. Radiology 1986;158:653-8.

17 Al Jarad N, Poulakis N, Pearson MC, Rubens MB, Rudd RM. Assessment of asbestos-related pleural disease by computed tomography, a comparison with the chest radiograph. Respir Med 1991;85:203-8.

18 Muller NL, Staples CA, Miller RR, Abboud RT. "Density mask"-an objective method to quantitate emphysema using computed tomography. Chest 1988;94:728-87.

19 Kinsella M, Muller NL, Abboud RT, Morrison NJ, DyBuncio A. Quantitation of emphysema by computed tomography using a "density mask" program and correlation with pulmonary function tests. Chest 1990;97:315-21.

20 Gould GA, MacNee W, Mclean A, Warren PM, Redpath A, Best JJK, et al. CT measurements of lung density in life can quantitate distal airspace enlargement-an essential defining feature of human emphysema. Am Rev Respir Dis 1988;137:380-92.

Accepted 19 August 1991

From 1 July 1985 articles submitted for publication will not be returned. Authors whose papers are rejected will be advised of the decision and the manuscripts will be kept under security for three months to deal with any inquiries and then destroyed. 